\title{
Resenhas
}





\section{Uma alternativa para o capitalismo?}

Luiz Carlos Bresser-Pereira I

$\mathrm{D}$ ESDE a queda do Muro de Berlim, em 1989, seguida pelo colapso da União Soviética, em 1991, o capitalismo triunfou sobre o "socialismo" - na verdade, sobre o estatismo -, que deixou de ser uma forma alternativa de organização econômica e social das sociedades modernas. Isso não obstante fosse sabido que, de acordo com a terminologia de Marx, o modo de produção dominante nos países comunistas não era o socialismo - não era a sociedade democrática e igualitária, a sociedade sem classes -, mas algo que eu, há muito, denominei "modo de produção tecnoburocrático ou estatal" - uma forma de organização econômica e social onde havia mais igualdade econômica do que no capitalismo, mas não havia democracia nem se podia falar em sociedade sem classes porque a tecnoburocracia substituíra a burguesia no papel de classe dominante.

$\mathrm{Na}$ verdade, o socialismo começou a se revelar inviável quatro anos depois da Revolução Socialista de 1917, quando Lenin decidiu fazer uma abertura para o capitalismo com sua Nova Política Econômica. Entretanto, isso só se tornou claro quando Stalin estava no poder. Primeiro, porque a "ditadura do proletariado" revelou-se uma estratégia permanente de dominação; e, segundo, porque o comando dessa ditadura não coube ao povo ou aos trabalhadores, mas à classe tecnoburocrática ou profissional. Essa sociedade tecnoburocrática na qual a relação de produção era a organização (a propriedade coletiva dos meios de produção pela tecnoburocracia) foi bem-sucedida no plano econômico enquanto se tratava de instalar o setor por definição não competitivo da economia (a infraestrutura e a indústria pesada), mas falhou quando, a partir de meados dos anos 1960, o desafio era a diversificação através de um número infinito de empresas que formam o setor competitivo da economia. Para esse setor o planejamento estatal era altamente ineficiente quando comparado com a coordenação pelo mercado. O estatismo fracassou por essa razão; porque se revelou uma forma de organização econômica e social menos eficiente do que o capitalismo. O controle pela tecnoburocracia da sociedade foi mantido na China porque sua elite dirigente percebeu que o modelo centralizado e planejado havia esgotado suas possibilidades, e tratou de colocar uma grande parte de sua economia sob a coordenação do mercado.

O capitalismo venceu sua competição com o estatismo porque era mais eficiente, e, ao vencer, tornou o ideal socialista mais longínquo, não obstante esse ideal houvesse sido abandonado pela União Soviética muito tempo antes do seu $\mathrm{CO}^{-}$ lapso. Hoje o capitalismo impera em toda parte, tudo se tornou mercadoria, quase tudo se submeteu à lógica do lucro e da acumulação de capital, ou seja, à lógica do mercado. Ao socialismo democrático, coordenado pelo Estado e pelo mercado, resta a utopia insuperável, mas que enfrenta o paradoxo de que só será viável no dia em que sua promessa maior - a da razoável igualdade econômica e de conhecimento entre os seres humanos seja alcançada.

Expresso sumariamente essa minha visão das coisas para procurar entender e 
apresentar a meus leitores o último livro de Fábio Konder Comparato, A civilização capitalista. O autor tem a minha idade, foi como eu aluno dos jesuítas e da Faculdade de Direito do Largo de São Francisco. Ele se tornou um notável professor de Direito e um crítico ético severo da sociedade em que vivemos; eu me tornei um economista político buscando compreender o mundo em que viemos.

Como o nome de seu livro já deixa claro, Comparato vê o capitalismo como uma civilização - como a primeira civilização universal -, e é tão ou mais crítico dela do que eu. O capitalismo pode ser relativamente eficiente, certamente mais eficiente do que os modos de produção anteriores, como seu maior crítico e maior analista, Marx, bem remarcou. Mas é um sistema intrinsecamente injusto e corrupto. Conforme o juízo ético que Comparato faz no final de seu livro, os malefícios permanentes do capitalismo são, em primeiro lugar, a sistemática exploração dos trabalhadores e dos consumidores. Para ele, "Marx não soube prever um malefício bem maior [do que o produzido pelo mecanismo da mais-valia], o qual só veio se concretizar nas últimas décadas: a progressiva dispensa da força de trabalho no funcionamento do sistema" (p.272). Em segundo lugar, os atentados ao equilíbrio ecológico do planeta. "A apropriação do meio natural pela espécie humana rompeu o indispensável equilíbrio ecológico e ameaça o futuro da biosfera do planeta" (p.274). Terceiro, as atrocidades do colonialismo capitalista. Quarto, os efeitos nocivos em matéria de saúde pública, como o poderio da indústria do tabaco demonstra: "o lobby do tabaco atuou no mundo inteiro, e até mesmo no seio das organizações internacionais" (p.279).
Entretanto, não está aí a força deste livro, mas na afirmação de uma tese central. Ao contrário das outras civilizações, a civilização capitalista é universal. As outras civilizações estavam "umbilicalmente ligadas à sua localização geográfica" (p.20). Tivemos as

civilizações fluviais, como a chinesa, surgida ao longo do rio Amarelo (Huang Hê); a indiana, ao longo do rio Indo; a civilização mesopotâmica dos sumérios, babilônios e assírios; e a civilização do antigo Egito, largamente tributária do Nilo. Do mesmo modo não é difícil reconhecer civilizações maritimas, dentre as quais ocupou lugar de destaque a civilização europeia, centrada em torno do mar Mediterrâneo. Há também civilizações oceânicas, como as que floresceram na Ilha de Páscoa, no Havaí, na Austrália e na Nova Zelândia, regiões durante longo tempo isoladas, sem qualquer contato com o mundo exterior; civilizações do deserto, como a dos primeiros povos árabes; ou então civilizações de montanha, como a andina e a tibetana. (p.22)

Mas, adverte Comparato, "as civilizações evoluem tanto mais rapidamente quanto mais contatos mantenham umas com as outras", e, para isso, utilizaram as facilidades oferecidas pelos rios, pelos mares e pelas estepes, mas “a dominação dos mares e a utilização das estepes e dos grandes rios, como verdadeiras estradas naturais, só foi possível graças a algumas invenções técnicas decisivas, tais como a arte da navegação, a fabricação dos primeiros veículos terrestres e a utilização dos animais de sela e de carga" (p.22-3).

Depois dessa Introdução, no primeiro capítulo do livro, Comparato vai discutir “o espírito do capitalismo". Para 
isso usa o método ou a filosofia da história que expôs na Introdução. Para ele, uma sociedade ou uma civilização possui três elementos:

1) a base geoeconômica, ou seja, o território onde ela se assenta; 2) a mentalidade e o sistema ético, que poderíamos denominar, na linha de Max Weber, o espírito de uma civilização - vale dizer, a visão de mundo e os valores predominantes que regem a vida coletiva, juntamente com o acervo de suas criações culturais; e 3) a hierarquia social e as instituições de poder, isto é, a organização dos grupos sociais que exercem o comando, e os meios ou instrumentos utilizados para tanto.

De acordo com a visão clássica do materialismo histórico, essas três esferas ou instâncias da sociedade são, para Comparato, interdependentes. Muito diferentemente, não há no seu modelo uma instância propriamente econômica, mas uma instância geoeconômica: o território. O que realmente importa para ele, de acordo com o idealismo filosófico, é a mentalidade, no sentido da Escola dos Annales, e principalmente, o espírito de um povo, nos termos de Hegel. Para ele, o juízo ético, que "não é feito somente de razão, mas também de indignação e vergonha, de ternura e compaixão" (p.19), O fundamental é a "consciência coletiva" (de Émile Durkheim). As mentalidades que formam as culturas nacionais "engendram costumes, ou seja, modos de vida constantes e uniformes, largamente observados em uma sociedade, em geral de forma irrefletida, como se fossem automatismos sociais" (p.34). O modelo ético das civilizações antigas, sua regra de ouro, inscrita em todas as grandes religiões, na República de Platão, e no Anacleto de Confúcio, pode ser

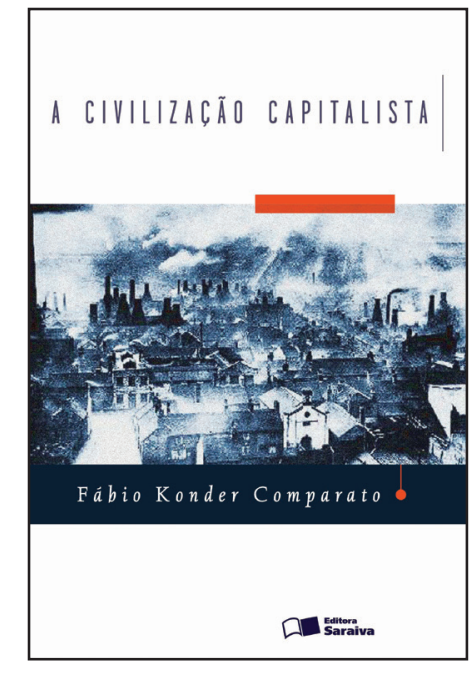

\section{COMPARATO, F. K. A civilização capitalista. São Paulo:}

Saraiva, 2013. 312p.

traduzido na lição deste último, “o que não quiseres que seja feito a ti, não faças a outrem". Não é essa a ética do capitalismo: "o princípio ético supremo passou a ser a busca, por cada indivíduo, do próprio interesse material, deixando-se o bem-comum e os preceitos éticos em segundo plano" (p.48). A submissão da esfera pública à privada vai ser sua característica fundamental. $\mathrm{O}$ individualismo torna-se todo-poderoso.

É preciso, entretanto, assinalar que o reconhecimento da autonomia individual foi um grande avanço.

O reconhecimento da autonomia da consciência individual em matéria religiosa, afirmada pelos grandes Reformadores do século XVI, foi, sem sombra de dúvida, a matriz dos direitos humanos de caráter individual, que vieram a ser consagrados com o Bill of Rights de 1689, e as Revoluções Norte-Americana e Francesa do fim do século seguinte... 
No entanto, por uma dessas ironias em que abunda a história, a era da autonomia da consciência individual teve pouca duração. Já em meados do século XVIII, com a decisiva intervenção da máquina a vapor, tinha início a Revolução Industrial, que foi o primeiro passo para a construção da sociedade de massas no mundo inteiro, com o predomínio da mentalidade coletiva other directed, ou seja, submetida à dominação ideológica alheia. Doravante as grandes massas passaram a ser manipuladas pelos detentores do poder. (p.63-4)

Nesses termos, Comparato analisa devidamente a Revolução Industrial, mas não a vê como o elemento fundamental da revolução capitalista. Nos capítulos seguintes ele vai contar a história do capitalismo, vai discutir em um grande esforço de síntese o capitalismo mercantil, o industrial e o pós-industrial. Mas a abordagem é gradualista; a ideia de uma revolução capitalista não está presente. Ou não está explícita, embora ela tenha sido tão importante quanto foi a outra grande "revolução" da história humana, a descoberta da agricultura e a transformação dos povos, de coletores em agricultores capazes de produzir um excedente econômico que deu origem às grandes civilizações antigas. Comparato reconhece, porque é essencial para sua tese central, que o capitalismo se diferenciará de forma decisiva das anteriores civilizações ao ser uma forma de organização econômica e social não associada a um determinado território, mas universal. Em outras palavras, o objetivo de todas as sociedades que ainda não realizaram sua revolução nacional e industrial, que não formaram seu Estado-nação e se industrializaram, assim completando sua revolução capitalista, é o de copiar a tec- nologia e as instituições dos países ricos e também se desenvolverem.

Naturalmente, ao discutir o capitalismo industrial, Comparato discute a Revolução Industrial, sua base no surto comercial e na reforma agrária, o salto tecnológico que representou a invenção da máquina a vapor, a aceleração do desenvolvimento tecnológico, o surgimento de relações impessoais, o advento das sociedades de massa, a urbanização crescente, a progressiva emancipação das mulheres, a criação da escola pública e a generalização do ensino fundamental, e a convivência forçada de diferentes grupos étnicos e religiosos.

O capítulo 6 é dedicado ao capitalismo pós-industrial, que eu prefiro chamar capitalismo tecnoburocrático, para salientar o papel fundamental que passa a assumir a nova classe média profissional pública e privada após a Segunda Revolução Industrial, no final do século XIX. O conceito de pós-industrial destina-se a salientar o aumento permanente da participação dos serviços na renda nacional. Mas há pouca relação do aumento da participação dos serviços com os fenômenos mais importantes que ocorrem no pós-guerra e no último quartel do século $\mathrm{XX}$, que Comparato analisa nesse capítulo. No pós-guerra, temos a formação de um capitalismo social-democrático e desenvolvimentista, que é o resultado de um grande compromisso de classes e que se revela poderoso em reformar o capitalismo, seguido da globalização e da contrarrevolução neoliberal, por meio da qual uma coligação financeiro-rentista tenta monopolizar o poder nas sociedades capitalistas.

No capítulo 7, Comparato faz o juízo ético da civilização capitalista. Para ele, 


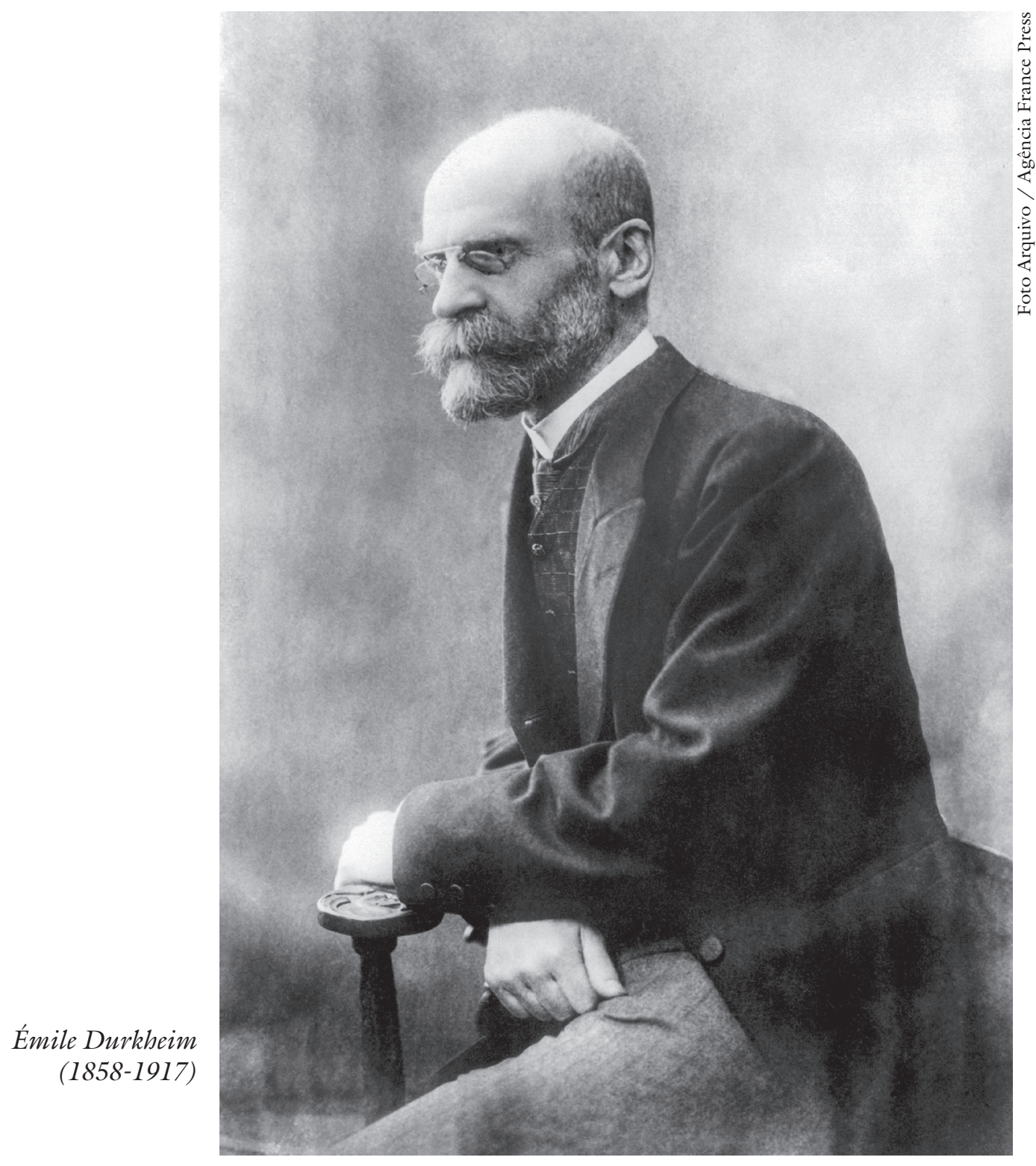

seus malefícios são muito grandes. Mas isso não o leva a prever o seu desaparecimento no curto prazo: “a civilização capitalista não desaparecerá subitamente por efeito de uma revolução; o seu decesso será precedido de um longo período de agonia" (p.281). Como "o capitalismo encarna a primeira e única civilização mundial na história... sua capacidade de resistência à mudança é incomparavelmente maior do que as civilizações que a precederam" (p.267).
Comparato é otimista. Fiel a seu método, ele está convencido de que o capitalismo será superado no plano ético.

A civilização que irá suceder à capitalista começou a partir da "crise da consciência europeia” a que me referi linhas atrás [Paul Hazard, 1961, La crise de la conscience européenne 1680-1715]. E sua linha de desenvolvimento estabeleceu-se em torno da dignidade suprema da pessoa humana, como fundamento de toda 
a vida ética... A decrepitude de uma civilização começa justamente quando os seus valores fundamentais, aos quais correspondem as instituições de poder social, já não contam com a adesão da maioria, e novos valores éticos passam a formar a mentalidade coletiva. O pensamento crítico exerce então, como frisou Marx, um papel transformador, suscitando a geral indignação contra o estado de coisas até então vigente; ou seja, deslegitimando o sistema de poder em vigor.

Não posso deixar de me identificar e de me solidarizar com essa perspectiva, mas para mim é difícil acreditar que seja possível mudar a sociedade mediante a indignação da moral. Em adição, é necessário um projeto que envolva uma nova forma de organização econômica e social, baseada, por exemplo, na autogestão das empresas. Marx e Engels disseram no Manifesto comunista que os povos só se dispõem a lutar por uma ideia quando percebem que as condições para implementá-la já estão presentes. Pensavam que as condições para o socialismo estavam então presentes. Enganavam-se. Hoje, mesmo nos países mais desenvolvidos, as condições para a autogestão são limitadas. Não existe, portanto, uma proposta viável de mudança social. Comparato quer que o "o espírito comunitário forme o núcleo da futura civilização humanista" (p.293). Ao fazer esse voto, ele parte do pressuposto de que o ser humano não é simplesmente egoísta. Na medida em que ele é um ser social, ele obedece, além do princípio da sobrevivência, ao princípio da convivência. Uma combinação de egoísmo e de altruísmo é sempre possível e necessária. Mas não basta isso, como também não basta o espírito republicano de dis- tinguir o interesse público do interesse pessoal. É preciso também um plano de voo - um plano que ainda não está disponível para a humanidade; não porque não temos quem possa defini-lo, mas porque não temos ainda as condições humanas necessárias para pô-lo em prática. O capitalismo é o resultado de um pacto faustiano, ainda não estamos preparados para realizar um pacto humano, mas obras corajosas e capazes como esta de Fábio Konder Comparato são um caminho nessa direção.

Luiz Carlos Bresser-Pereira é professor emérito da Fundação Getulio Vargas (SP). @ - bresserpereira@gmail.com

I Fundação Getulio Vargas. São Paulo/ SP, Brasil. 